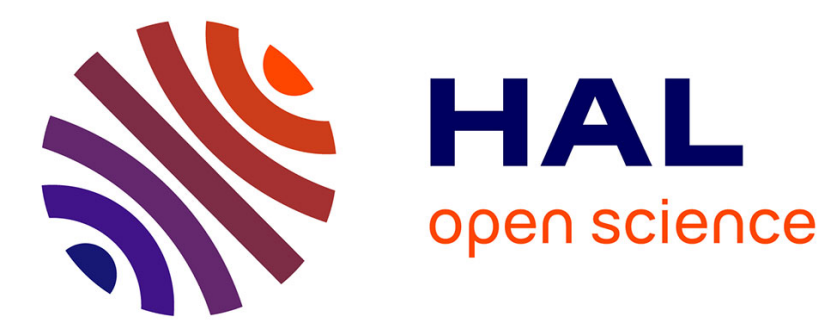

\title{
Structural Analysis of Molybdenum Bronzes
}

T. Tanaka, H. Aritani, S. Yoshida, K. Eda, N. Sotani, S. Hasegawa

\section{To cite this version:}

T. Tanaka, H. Aritani, S. Yoshida, K. Eda, N. Sotani, et al.. Structural Analysis of Molybdenum Bronzes. Journal de Physique IV Proceedings, 1997, 7 (C2), pp.C2-1143-C2-1144. 10.1051/jp4:19972164. jpa-00255228

\section{HAL Id: jpa-00255228 https://hal.science/jpa-00255228}

Submitted on 1 Jan 1997

HAL is a multi-disciplinary open access archive for the deposit and dissemination of scientific research documents, whether they are published or not. The documents may come from teaching and research institutions in France or abroad, or from public or private research centers.
L'archive ouverte pluridisciplinaire HAL, est destinée au dépôt et à la diffusion de documents scientifiques de niveau recherche, publiés ou non, émanant des établissements d'enseignement et de recherche français ou étrangers, des laboratoires publics ou privés. 


\title{
Structural Analysis of Molybdenum Bronzes
}

\author{
T. Tanaka, H. Aritani, S. Yoshida, K. Eda, N. Sotani and S. Hasegawa \\ Department of Molecular Engineering, Kyoto University, Sakyo-ku, Kyoto 606-01, Japan
}

\begin{abstract}
Hydrogen molybdenum bronzes, $\mathrm{H}_{0.21} \mathrm{MoO}_{3}$ (type I) and $\mathrm{H}_{0.91} \mathrm{MoO}_{3}$ (type II) were characterized by Mo $\mathrm{K}$-edge XAFS spectroscopy. XANES specetra showed that type $I$ has an axially symmetric $\mathrm{MoO}_{6}$ unit which is mainly conncted to each other with vertices sharing and a $\mathrm{MOO}_{6}$ unit in type $\mathrm{II}$ are similar to that in $\mathrm{MoO}_{2}$. EXAFS spectra suggested that the MoOx sheet in type I is similar to $\mathrm{MoO}_{3}$ while in type II, a MoOx sheet is similar to that in rutile $\mathrm{MoO}_{2}$ in which $\mathrm{MoO}_{6}$ is conneced to form a chain by sharing the edges of opposite sides. The curve fitting analysis of Mo-O bonds for type $I$ supported the earlier results obtained from diffraction and IR methods; a $\mathrm{MoO}_{6}$ unit has $C_{4 v}$ symmetry. In case of type II, $D_{4 h}$ structure is possible and hydrogen is captured by $\mathrm{Mo}=\mathrm{O}$ bonds resulting in the formation of $\mathrm{Mo}-\mathrm{OH}$ bonds.
\end{abstract}

\section{INTRODUCTION}

Hydrogen molybdenum bronze, $\mathrm{H} x \mathrm{MoO}_{3}$, is classified to four phases depending on included hydrogen [1]; type-I (orthorhombic) $0.21<x<0.4$ [2], type II (monoclinic) $0.85<x<1.04$, type III (monoclinic) $1.55<x<1.72$ and type IV (monoclinic) $x=$ 2. Type I has a layered structure in which a layer consists of two MoOx sheets. The $\mathrm{MoO}_{6}$ units connecting to each other with vertices (corner) sharing in the sheet have been proposed to be in an axially symmetric moiety deduced from the result of infrared absorption (IR) [3,4] and ${ }^{1} \mathrm{H}$ NMR studies [5]. The other monoclinic phases are not fully characterized. The present paper is devoted to analysis of the local structure of hydrogen molybdenum bronzes types I and II by means of Mo K-edge XAFS spectroscopy.

\section{EXPERIMENTAL}

Types I and II were prepared by reduction of $\mathrm{MoO}_{3}$ in an acidic media according to the Glemser's method [1]. The formation of types I and II are confirmed by XRD [1] and the hydrogen contents were $x=0.21$ and $x=0.91$, respectively [3].

XAFS spectra were taken by EXAFS facility installed on BL-10B at Photon Factory (ting energy $2.5 \mathrm{GeV}$ and stored current $360-270 \mathrm{~mA}$ ) in National Laboratory for High Energy Physics, Tsukuba (Proposal No. 94G002) with a Si (311) channel cut monochromator. The data reduction was performed [6] at the Data Processing Center of Kyoto University.

\section{RESULTS AND DISCUSSION}

\subsection{XANES spectra}

Figure 1 shows normalized XANES spectra of the samples and some reference complexes. For XANES spectrum of type I, the pre-edge peak due to $1 s$ to $4 d$ transition is seen and the intensity is almost the same as that of $\mathrm{MoO}_{2}(\mathrm{acac})_{2}$ with $D_{4 h}$ symmetry, in which four $O$ atoms from acetylacetonato groups are located at square apexes and two $O$ atoms of molybdenyl are at the vertical axis. The pre-edge peak intensity is lower than that of $\mathrm{MoO}_{3}$ in which a Mo ion is located at the center of a much distorted oxygen octahedron, indicating that Mo ions in type $I$ is located at the center of highly symmetric moiety. Twin peaks at post-edge regions are found at the similar positions to that found in the case of $\mathrm{MoO}_{2}(\mathrm{acac})_{2}$ although the intensities are slightly different. This is possibly due to the positions of axial $O$ atoms as Sotani et al. reported $[2,3]$; i.e, in type $I$ with $C_{4 v}$ symmetry, one $\mathrm{O}$ at an axial position is of a $\mathrm{Mo}=\mathrm{O}$ bond and the other is a bridging oxygen. On the other hand, the spectrum of type II is totally similar to that of $\mathrm{MoO}_{2}$ of rutile structure. The pre-edge peak for $\mathrm{MoO}_{2}$ was almost missing this is mainly due to

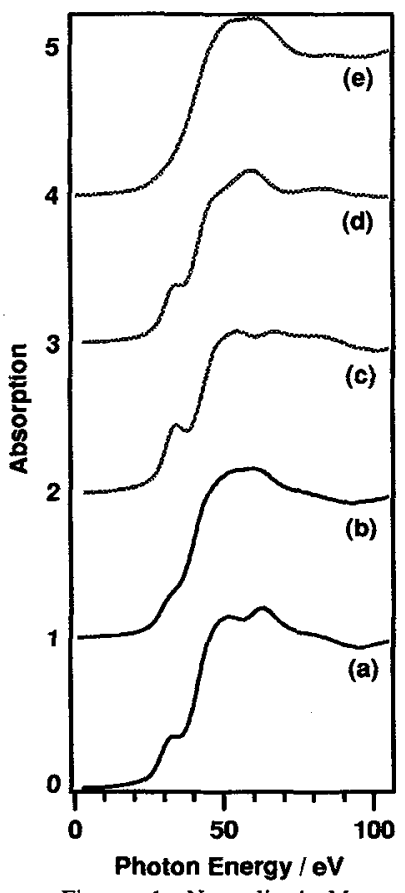

Figure 1 Normalized Mo K-edge XANES Spectra of (a) type I, (b) type II, (c) $\mathrm{MoO}_{3}$ (d) $\mathrm{MoO}_{2}(\text { acac })_{2}$ and (e) $\mathrm{MoO}_{2}$. Energy offset is taken to be $19960 \mathrm{eV}$ 
the valence of Mo in an axial symmetry. The weak shoulder peak due to $1 s$ to $4 d$ transition for type II reveals that $\mathrm{Mo}$ is located at a more symmetric center than that of type I and/or Mo is partly reduced from hexavalence. Type II, $\mathrm{H}_{0.91} \mathrm{MoO}_{3}$, has a molybdenum ions the formal charge of which is almost $5+$.

\subsection{EXAFS Spectra}

Figure 2 shows Fourier transforms of $k^{3}$-weighted EXAFS spectra. The peaks found in a region 1-2 $\AA$ are due to the scattering from adjacent $\mathrm{O}$ atoms in all spectra. As found in the cases of $\mathrm{MoO}_{2}$ and $\mathrm{MoO}_{2}(\mathrm{acac})_{2}$, the complex with small divergency of $\mathrm{Mo}-\mathrm{O}$ bonds exhibits intense peaks. From this point of view, Mo-O divergency is high in the cases of types I and II. The peaks found at $2-4 \AA$ are due to the scattering from adjacent $\mathrm{Mo}$ atoms. In case of $\mathrm{MoO}_{3}, \mathrm{MoO}_{6}$ units are linked with edges and vertices sharing and the nearest Mo-Mo distances are diverging resulting in the weak intensities in the region $2-3 \AA$. Therefore contribution of Mo-Mo scattering is mainly due to the adjacent $\mathrm{Mo}$ ions in $\mathrm{MoO}_{6}$ unit connecting with vertices sharing. This type of $\mathrm{MoO} x$ sheet is similar to that of type I. On the other hand, $\mathrm{MoO}_{2}$ of a rutile structure has a regular Mo-Mo atomic distances 2.51 and 3.51 $\AA$, which is reflected to twin Mo-Mo peaks in the region $2-4 \AA$. The same feature can be seen for the case of type II, suggesting that $\mathrm{MOO}_{6}$ unit in type II is connected to each other with not only vertices sharing but also edge sharing as found in the rutile structure.

Table 1 Curve fitting results of Mo-O in the sample

\begin{tabular}{ccccc}
\hline sample & $\mathrm{CN}$ & $\mathrm{R} / \AA$ & $\Delta \sigma^{2} / \AA^{2}$ & Refinement \\
\hline type I & $0.6(5)$ & $1.64(1)$ & $0.0019(6)$ & $3.6 \%$ \\
& $4.1(4)$ & $1.97(2)$ & $0.0027(4)$ & \\
& $1.0(5)$ & $2.40(2)$ & $0.0027(4)$ & \\
\hline \multirow{2}{*}{ type II } & $1.5(5)$ & $1.84(1)$ & $0.0021(8)$ & $8.6 \%$ \\
& $3.9(5)$ & $2.01(1)$ & $0.0055(7)$ & \\
\hline
\end{tabular}

The empirical parameters from $\mathrm{K}_{2} \mathrm{MoO}_{4}$ were used. The values in parentheses are standard deviation. $\Delta \sigma^{2}$ is the relative Debye Waller factor.

The curve fitting analysis was carried out [6] for the Mo-O bonds and the result are given in Table 1 . In case of type I, the presence of three kinds Mo-O was concluded. The shortest is possibly due to $\mathrm{Mo}=\mathrm{O}$ which faces to the interlayer and four $O$ atoms are located in the sheet. The longest is due to the $O$ atoms at the opposite vertex of Mo=O. The result is well consistent with that deduced from IR analysis $[2,3]$. In case of type 1 , two shell fitting gave the satisfactory result. The longer Mo-O bonds are equatorial. The shorter were axial corresponding to $\mathrm{Mo}=\mathrm{O}$ in type $\mathrm{I}$. The elongation of this bond is caused by the $\mathrm{H}$ intercalations resulting in the formation of $\mathrm{Mo}-\mathrm{OH}$. Therefore, $D_{4 h}$ structure for a $\mathrm{MoO}_{6}$ unit as in the case of $\mathrm{MoO}_{2}(\mathrm{acac})_{2}$ is very likely. The structure is basically the same as that found in $\mathrm{MoO}_{2}$.

From the results mentioned above we concluded the structure of type I and type II as follows. Type I has a layered structure in which MoOx sheet similar to that in $\mathrm{MoO}_{3}$ and the $\mathrm{MoO}_{6}$ unit is more regular symmetric $\left(C_{4 v}\right)$. This is well consistent with the earlier result from diffraction technics [1,7,8] and IR [2,3]. In type II, $\mathrm{MoO} x$ sheet is similar to that in $\mathrm{MoO}_{2}$ in which $\mathrm{MoO}_{6}$ is connected to form a chain by sharing the edges of opposite sides.

\section{References}

[1] Birtill J. J., Dickens P. C. Mater. Res. Bull. 13 (1978) 311

[2] Sotani N., Kawamoto Y., Inui M. Mater. Res. Bull. 18 (1983) 797.

[3] Sotani N., Eda K., Sadamatsu M., Takagi S., Bull. Chem. Soc. Jpn. 62 (1989) 903.

[4] Sotani N., Yoshida N., Yoshioka N., Kishimoto S., Bull. Chem. Soc. Jpn. 58 (1985) 1626.

[5] Sotani N., Eda K., Kunimoto M., J. Chem. Soc., Faraday Trans. 86 (1990) 1583.

[6] Tanaka T., Yamashita H., Tsuchitani R., Funabiki T., Yoshida S. J Chem. Soc., Faraday Trans. I 84 (1988) 2987.

[7] Dickens P. G., Birtill J. J., Wright C. J. J. Solid State. Chem. 28 (1979) 185.

[8] Hibble S. J., Dickens P. G. Ber. Bunsen-Ges. Phys. Chem. 90 (1986) 702.
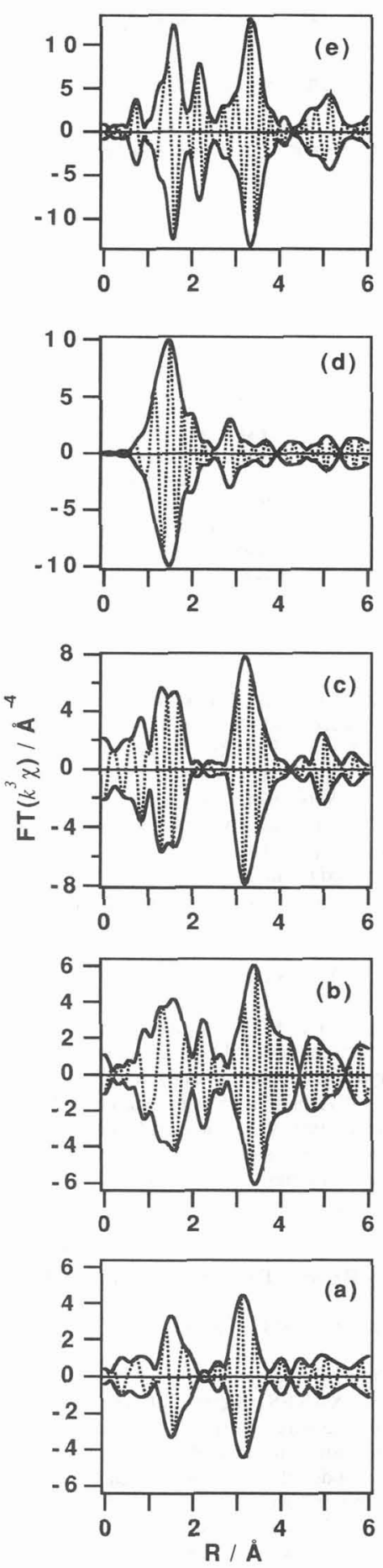

Figure 2 Fourier transforms of EXAFS of Mo compounds. (a)-(e), see captions to Fig. 1 